\title{
The Antibiotic Relationships of Some Yeasts from Soil and Leaves
}

\author{
By MARGARET E. DI MENNA \\ Soil Bureau, Department of Scientific and Industrial Research, Wellington, \\ New Zealand
}

(Received 30 May 1961)

SUMMARY

The antibiotic powers of some common soil and leaf bacteria, streptomyces and moulds were tested against soil and leaf yeasts. Twelve of the seventeen bacteria used, ten of the eleven streptomyces strains and seven of the twenty-two moulds were inhibitory. Pseudomonas chlororaphis, Aeromonas sp., five streptomyces and Trichoderma viride inhibited $70 \%$ or more of the twenty-five yeast species used. The most frequently isolated soil yeasts were amongst those most sensitive to antibiotics. Only one species of leaf yeast but several soil yeasts were inhibited by leaf bacteria and moulds. As streptomyces do not occur on leaves, it seems that the wide seasonal fluctuations in kinds and numbers of yeasts on leaves are due rather to nutritional and physical factors than to antibiotic ones.

\section{INTRODUCTION}

In New Zealand it has been found that the soil yeast flora varies qualitatively from place to place with soil type and vegetation but not with season (di Menna, $1955,1957,1958,1960 a, b)$, whilst the yeast flora on the leaves of pasture plants changes in type with season but not with locality (di Menna, 1959a). Yeasts from pasture leaves reach the soil under them in large numbers but are unable to grow there or even to survive for long (di Menna, 1960 b). An examination of some physiological characters of soil and leaf yeasts showed little difference between the two groups (di Menna, 1959 $b$ ), so it was suggested that antagonistic factors originating from other members of the soil population kept the two floras distinct. The present work reports a study of some interactions between yeasts common in soil or on leaves and the bacteria, streptomyces and moulds which have been found to occur most frequently in soil and on pasture plant leaves in New Zealand.

\section{ORGANISMS USED}

The yeasts used as test organisms were much the same as those used in the examination of physiological characters (di Menna, 1959 b). Some modifications of the list, deletions, additions and changes in probable habitat, have been made with progress in the survey work. Twenty-five species were used, eleven from soil, seven from leaves, and seven whose habitat is still uncertain but which have appeared sufficiently frequently in cultures from soil and leaves to warrant inclusion under the heading Uncertain Habitat. Two isolates of each species were used. 
From soil: Hansenula saturnus (Klocker) H. \& P. Sydow, H. californica (Lodder) Wickerham, H. mrakii Wickerham, Cryptococcus albidus (Saito) Skinner, C. diffluens (Zach) Lodder \& Kreger-van Rij, C. terreus di Menna, Candida humicola (Daszewska) Diddens \& Lodder, C. curvata (Diddens \& Lodder) Lodder \& Kreger-van Rij, C. muscorum di Menna, Trichosporon pullulans (Lindner) Diddens \& Lodder, T. cutaneum (de Beurm., Gougerot \& Vaucher) Ota.

From leaves: Sporobolomyces roseus Kluyver \& van Neil, Cryptococcus laurentii (Kufferath) Skinner, Torulopsis ingeniosa di Menna, Rhodotorula glutinis (Fres.) R. Harrison, R. mucilaginosa (Jorg.) Harrison, R. marina Phaff, Mrak \& Williams, R. graminis di Menna.

Uncertain habitat: Saccharomyces delbrueckii Lindner, Debaryomyces kloeckeri Guill. \& Peju, Cryptococcus luteolus (Saito) Skinner, Candida tropicalis (Cast.) Berkhout, C. guilliermondii (Cast.) Langeron \& Guerra, C. parapsilosis (Ashf.) Langeron \& Talice, Schizoblastosporion starkeyi-henricii Ciferri.

One isolate of each of the antagonist organisms was used. Eleven strains of bacteria from soil and six from leaves were selected and provided by Dr J. D. Stout (see Stout, 1958, 1960 $a, b$ ). The nomenclature is used according to Bergey's Manual (1957).

From soil: Pseudomonas chlororaphis, P. fluorescens, Aeromonas sp., Achromobacter sp., Aerobacter cloacae, Serratia sp., Bacillus cereus 'smooth' form, B. cereus 'rough' form, B. sphaericus, Nocardia sp., Myxococcus sp.

From leaves: Xanthomonas sp., Flavobacterium sp. 1, Flavobacterium sp. 2, Aerobacter sp., Micrococcus sp. 1, Micrococcus sp. 2.

Eleven strains of streptomyces from soil were used. Ten of these had been selected for their antibiotic producing ability and were provided by T. R. Vernon and one was provided by J. D. Stout. Three of these strains have subsequently proved to be of Streptomyces hygroscopicus and one of S. pilosus. Streptomyces are virtually absent from pasture plant leaves in New Zealand (T. R. Vernon, personal communication).

Fourteen moulds characteristic of soil and eight characteristic of leaves were selected and provided by R. H. Thornton (see Thornton, 1958, 1960).

From soil: Absidia glauca Hagem, Mortierella alpina Peyronel, M. elongata Iinm, Mucor hiemalis Wehmer, Zygorhynchus moelleri Vuill, Trichoderma viride Pers. ex Fr., Penicillium janthinellum Biourge, Gliocladium roseum Bain, Fusarium oxysporon Schlecht emend. Snyder \& Hansen, F. culmorum (W. G. Smith) Sacch., Cylindrocarpon radicicola Wr., Papulospora sp., Rhizoctonia sp., unidentified isolate SB 235.

From leaves: Hormodendron cladosporoides (Fr.) Sacc., Fusarium avenaceum (Fr.) Sacc., F. nivale (Fr.) Ces., Pithomyces chartarum (Berk. \& Curt.) M. B. Ellis, Stemphylium sp. and unidentified isolates LAA 190, LA 270 and HU 47.

In addition, the inhibitory effects of the following purified antibiotics were tested: gliotoxin, frequentin, patulin, viridin, mycophenolic acid and mixed Gliocladium roseum antibiotics (all supplied by Dr P. W. Brian, I.C.I. Laboratories, Welwyn, Hertfordshire, England), griseofulvin (Glaxo Laboratories, Greenford, Middlesex, England), actidione (Upjohn Co.) and polymyxin B sulphate (Pfizer Co.).

One medium was used, both for preliminary growth of the antagonists and for the growth of test organism with antagonist. This was the soy bean agar (SBA) of 
Smith, Gordon \& Clark (1952). All organisms used grew well on it, and although it is high in total nutrients it is low in reducing sugars (about $2.8 \mathrm{~g}$./1.) which may interfere with antibiotic phenomena. The final $\mathrm{pH}$ value of the cultures varied between pH 6 and 8.5, but was usually on the alkaline side of neutrality.

A slightly different technique was used with each group of antagonists. Bacteria were streaked across the dried surfaces of SBA plates, four streaks per $10 \mathrm{~cm}$. diam. plate. They were incubated for 4 days. Suspensions of yeasts in sterile tapwater were then spread between, but not touching, the bacterial colonies. There was no evidence that the preliminary bacterial growth had exhausted the nutrients in the medium.

Streptomyces were grown on SBA plates for 14 days. Plugs $0 \cdot 6 \mathrm{~cm}$. in diameter were cut from the cultures and placed, growth side uppermost, on SBA plates seeded with yeasts.

Moulds were grown on SBA plates for 7 days. Half the culture was then cut away along a diameter of each plate and replaced with sterile molten SBA. On this solidified surface yeast suspensions were streaked up to the cut edge of the mould culture.

Purified antibiotics were diluted to $1 / 1000$. Sterile water was used as a diluent, except for some of the sparingly water-soluble compounds where the primary dilution of $1 / 100$ was made up in a $1+4$ by vol. acetone + water mixture. Sterile filter paper disks soaked in antibiotic solution were placed on the surface of SBA plates seeded with yeasts.

All cultures were incubated at $20^{\circ}$. Yeast cultures used as inocula were 2-7 days old. Yeast-antagonist cultures were read after 2 days of incubation and read again after 3 days of incubation.

\section{RESULTS AND DISCUSSION}

Results are given in Tables 1, 2 and 3 and are summarized in Table 4.

Twelve of the seventeen bacterial strains used showed inhibitory powers. Aeromonas sp. was most active, strongly inhibiting all the yeasts tested except Trichosporon cutaneum which it inhibited only weakly. Pseudomonas chlororaphis also inhibited all yeasts, but inhibition of Candida muscorum and T. cutaneum was weak. Only seven of the twenty-two moulds showed antibiotic powers. Trichoderma viride was most active; Papulospora sp. and Cylindrocarpon radicicola were the only others used in which more than a very low degree of activity could be demonstrated. Eight of the eleven streptomyces used inhibited more than half the yeasts tested.

Actidione, gliotoxin and viridin were the most strongly zymostatic of the purified antibiotics used. Polymyxin B, frequentin and mixed Gliocladium roseum antibiotics were moderately so. The antibiotic spectrum of viridin was similar to that of the isolate of Trichoderma viride used. At a concentration of 1/1000 the purified antibiotic inhibited both isolates of Hansenula mrakii which the growing culture used did not affect; the culture did not inhibit any yeasts resistant to the antibiotic. Mixed Gliocladium roseum antibiotics inhibited eleven yeast isolates belonging to eight species but the culture of $G$. roseum used inhibited none. Either the method employed was unfavourable to the production of $G$. roseum antibiotics, or else the strain used produced antibiotics at only a low concentration.

Cryptococcus laurentii, C. albidus, C. luteolus, Candida curvata and Schizoblastosporion starkeyi-henricii were the most sensitive of the yeasts examined, being inhibited by twenty or more of the fifty antagonist organisms used. The least 


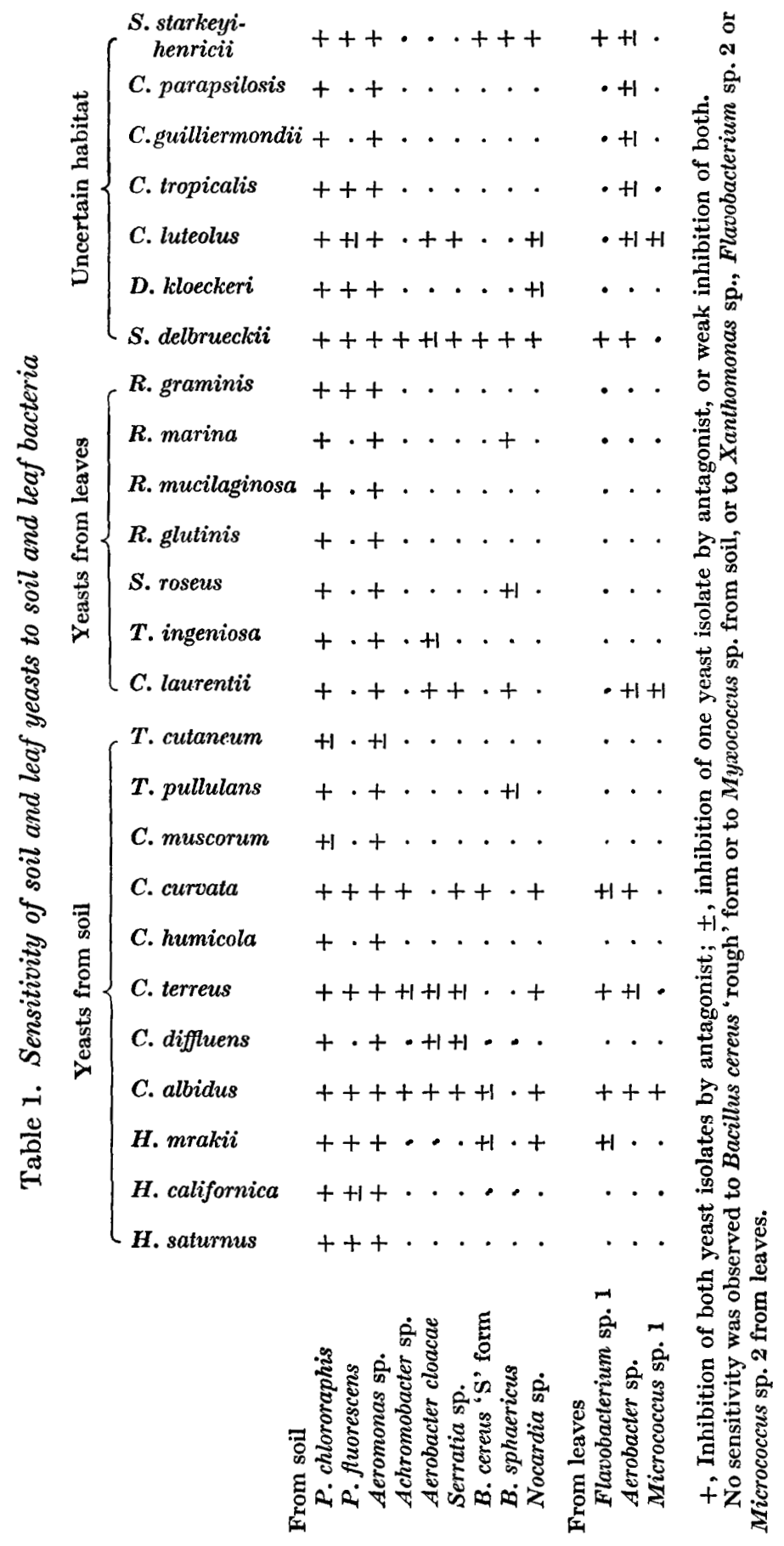




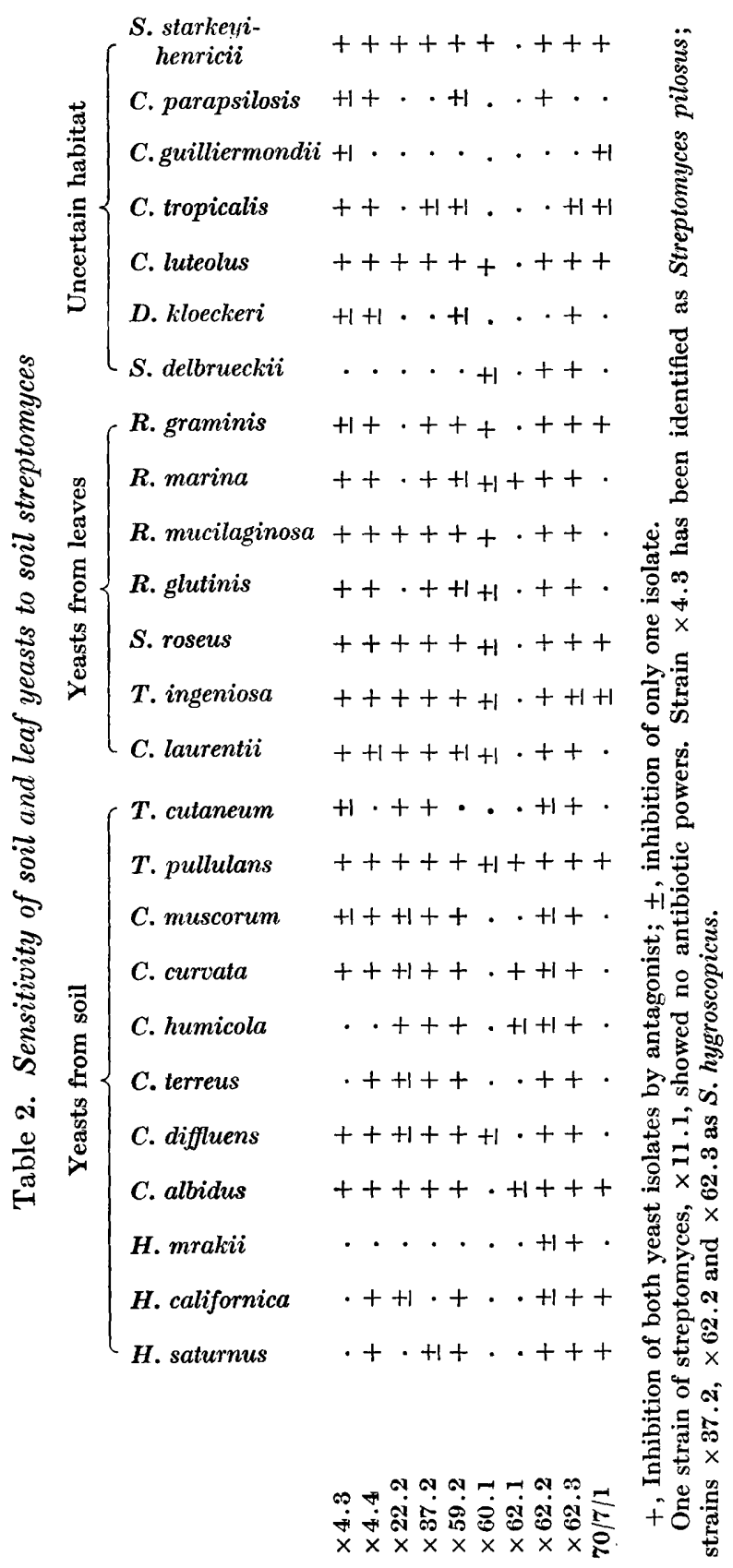




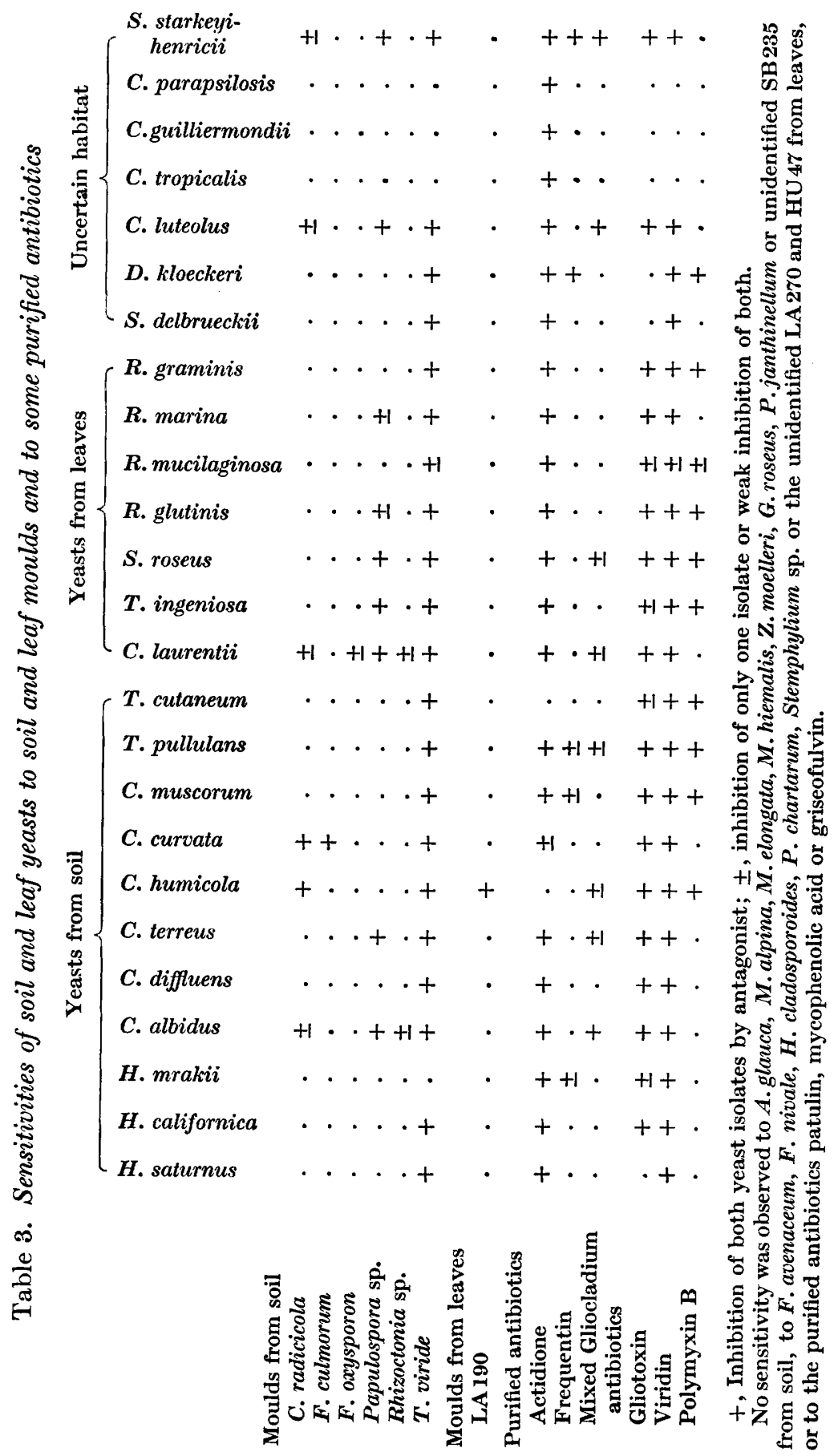




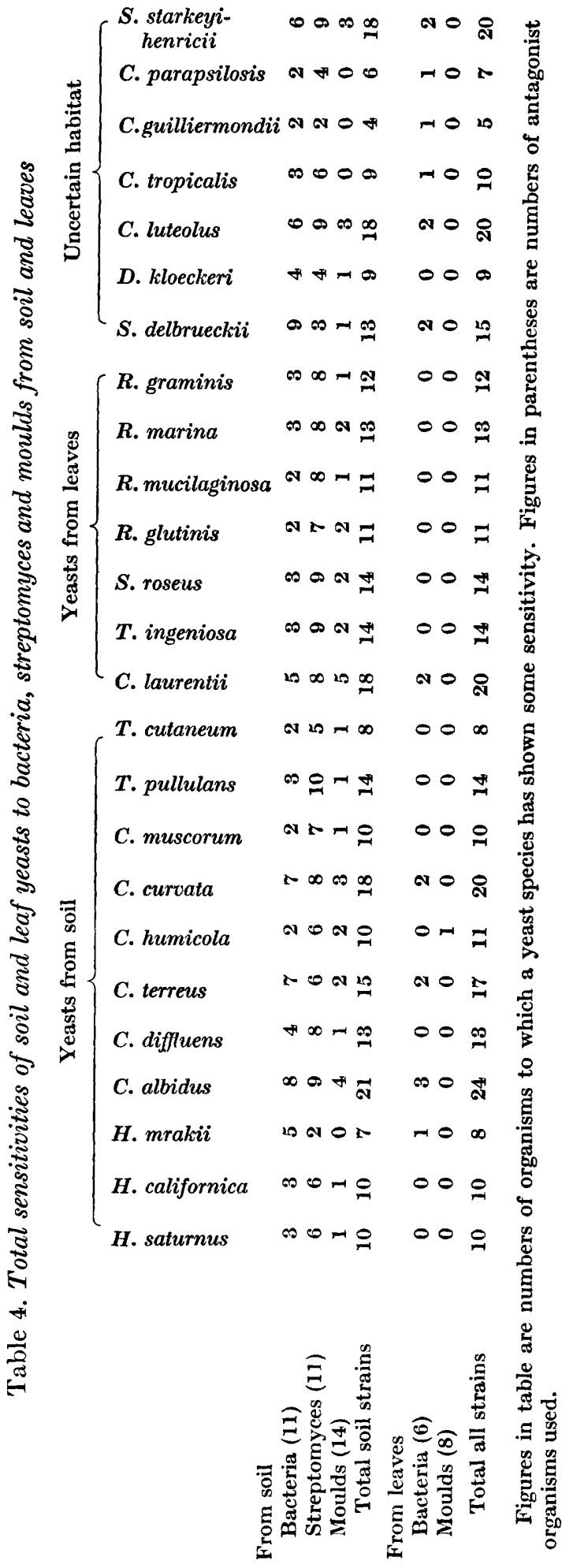


sensitive were Hansenula saturnus, $H$. californica, $H$. mrakii, Debaryomyces kloeckeri, Candida tropicalis, C. guilliermondii, C. parapsilosis, C. muscorum and Trichosporon cutaneum which were inhibited by ten or less. Some of these sensitivities are perhaps predictable in the light of what is known of yeast ecology, others seem paradoxical. Almost all the fermenting species tested (Hansenula spp., S. delbrueckii, D. kloeckeri, C. tropicalis, C.guilliermondii and C. parapsilosis) are included in the low sensitivity group. Fermenting yeasts generally appear to be commonest in habitats such as spoiling food, rotting fruit and fungus fruiting bodies, tree exudates and the animal gut, where nutrients are high, competition intense, and lack of sensitivity to antibiotics probably has high survival value.

Soil yeasts were relatively sensitive to antibiotics produced in vitro by other soil micro-organisms; indeed the most frequently isolated were the most sensitive. Of the soil yeasts with low sensitivities Hansenula spp. seem to be common in New Zealand only in those rarely occurring soils that are both water-logged and with a pH approaching neutrality (di Menna, $1960 \mathrm{~b}$; and unpublished). Candida muscorum has been found as the dominant yeast of only a few rather acid soils (Wright, 1959) where, according to the evidence of Jackson (1958), inhibitory effects will be decreased and resistance to antibiotics not a critical factor. Trichosporon cutaneum can be found in most New Zealand soils, but never as more than a small percentage of the total yeast population. It seems that resistance to antibiotics is not in itself of paramount importance in determining the ability of a yeast to live in soil.

It is perhaps significant that of the two rather similar soil species, Candida humicola and C. curvata, C. humicola was sensitive to eleven antagonist organisms and $C$. curvata to twenty. In New Zealand $C$. curvata has been the dominant yeast in a number of mineral soils and some acid peats. C. humicola on the other hand has been found mainly in the root zones of tussock plants (di Menna, 1958) and in the fermenting layer of forest litter (di Menna, 1960 b), both relatively rich and presumably competitive environments.

Leaf yeasts as a group were almost completely insensitive to either leaf bacteria or moulds. The only demonstrable effects were that one isolate of Cryptococcus laurentii was inhibited by Micrococcus sp. 1 and that both $C$. laurentii isolates were weakly inhibited by Aerobacter sp. Aerobacter sp. and Flavobacterium sp. 1 showed moderate antibiotic activity against soil yeasts and yeasts of uncertain habitat, but of the group of eight leaf moulds the only one with any inhibitory powers was the unidentified LA 190 which inhibited Candida humicola. Although leaf bacteria may prevent some soil yeasts from establishing themselves in the phyllosphere, it seems that the great quantitative and qualitative changes which occur seasonally in the leaf yeast population are due to alterations in physical conditions and availability of nutrients rather than to antibiotic activities of the rest of the leaf microflora.

Leaf yeasts as a whole appeared only slightly more sensitive to soil bacteria, streptomyces and moulds than soil yeasts, so that it seems as though antibiotics play little part in preventing leaf species from establishing themselves in soil. However, the data obtained here show only the antibiotic producing potentialities of the antagonists tested, not the pattern of antibiotic activity in soil. The effective antibiotic producers in soil may be, for instance, Papulospora sp. and the streptomyces $\mathrm{x} 4.3$ and $\mathrm{x60.1}$ which inhibit leaf rather than soil species. It will be necessary to work with soil itself to clarify this point. 
My thanks are due to Dr P. W. Brian (Akers Research Laboratories, Imperial Chemical Industries, Welwyn, Hertfordshire, England) for purified fungal antibiotics; to Dr T. R. Vernon (Plant Diseases Division, Department of Scientific and Industrial Research, Auckland, New Zealand) for cultures of streptomyces; to Dr J. D. Stout of this laboratory for cultures of bacteria, and to Dr R. H. Thornton, formerly of this laboratory, for cultures of moulds. This paper is Soil Bureau Publication no. 253.

\section{REFERENCES}

Bergey's Manual of Determinative Bacteriology (1957). 7th ed. Ed. by R. S. Breed, E. G. D. Murray \& N. R. Smith. London: Baillière, Tindall and Cox Ltd.

$J_{\text {ACKson, }}$ R. M. (1958). Some aspects of soil fungistasis. J. gen. Microbiol. 19, 390.

di Menna, M. E. (1955). A search for pathogenic species of yeasts in New Zealand soils. J. gen. Microbiol. 12, 54 .

Di Menna, M. E. (1957). The isolation of yeasts from soil. J. gen. Microbiol. 17, 678.

DI Menna, M. E. (1958). Biological studies of some tussock grassland soils. 3. Yeasts of three tussock grassland soils. N.Z. J. agric. Res. $1,939$.

Di Menna, M. E. (1959a). Yeasts from the leaves of pasture plants. N.Z. J. agric. Res. 2, 394.

Di Menna, M. E. (1959 b). Some physiological characters of yeasts from soil and allied habitats. J. gen. Microbiol. $20,13$.

DI Menna, M. E. $(1960 a)$. Biological studies of some tussock grassland soils. 14. Yeasts of two cultivated soils. N.Z. J. Agric. Res. 3, 207.

Di MEnNa, M. E. (1960b). Yeasts from soils under forest and under pasture. N.Z. J. agric. Res. 3, 623.

Smith, N. R., Gordon, R. E. \& Clark, F. E. (1952). Aerobic sporeforming bacteria. Monogr. U.S. Dept. Agric., no. 16.

Stout, J. D. (1958). Biological studies of some tussock grassland soils. 4. Bacteria. N.Z.J. agric. Res. 1, 943.

Stout, J. D. (1960a). Biological studies of some tussock grassland soils. 15. Bacteria of some cultivated soils. N.Z. J. agric. Res. 3, 214.

Stout, J. D. $(1960 b)$. Bacteria of soil and pasture leaves at Claudelands showgrounds. N.Z. J. agric. Res. 3, 413.

Thornton, R. H. (1958). Biological studies of some tussock grassland soils. 2. Fungi. N.Z. J. agric. Res. $1,922$.

Thornton, R. H. (1960). Biological studies of tussock grassland soils. 13. Fungi of two cultivated soils. N.Z. J. agric. Res. 3, 203.

Wright, A. C. S. (1959). Soils of Chatham Island. N.Z. Soil Bur. Bull. 19. 